\title{
The Child Is Father of the Man: Personality Continuities From Childhood to Adulthood
}

\author{
Avshalom Caspi \\ University of London and University of Wisconsin-Madison
}

\begin{abstract}
This article presents findings about continuities in personality development that have been uncovered in the Dunedin study, an investigation of a cohort of children studied from age 3 to 21 . At age 3, children were classified into temperament groups on the basis of observations of their behavior. In young adulthood, data were collected from study members themselves, from people who knew them well, and from official records. Undercontrolled 3-year-olds grew up to be impulsive, unreliable, and antisocial, and had more conflict with members of their social networks and in their work. Inhibited 3-year-olds were more likely to be unassertive and depressed and had fewer sources of social support. Early appearing temperamental differences have a pervasive influence on life-course development and offer clues about personality structure, interpersonal relations, psychopathology, and crime in adulthood.
\end{abstract}

My heart leaps up when I behold

A rainbow in the sky:

So was it when my life began;

So is it now I am a man:

So be it when I shall grow old,

Or let me die!

The Child is father of the Man;

And I could wish my days to be

Bound each to each by natural piety.

-William Wordsworth, "My Heart Leaps Up When I Behold"

Behavioral differences among children are apparent very early in life. Some children squirm and fuss when they are picked up; others like to be cuddled. Some children approach new situations with great zeal; others shrink from novelty. Are such behavioral differences, or temperamental styles, evanescent qualities or do they presage the life patterns to follow? Although many psychological theories subscribe to the view that what is past is prologue, this conjecture has been surprisingly difficult to substantiate empirically because it requires costly and time-consuming longitudinal studies that track people over time and across multiple developmental settings. As such, scientists, clinicians, and parents continue to wonder, is the child really the father of the man?

Avshalom Caspi, Social, Genetic and Developmental Psychiatry Research Centre, Institute of Psychiatry, University of London, London, England; and Department of Psychology, University of Wisconsin--Madison.

This work was supported by National Institute of Mental Health Grants MH-49414, MH-45548, and MH-45070. The Dunedin Multidisciplinary Health and Development Research Unit is funded by the Health Research Council of New Zealand. I am grateful to Phil Silva (Director), the unit investigators and staff, and the study members and their families. My thanks go to Terrie Moffitt and the reviewers for their comments about drafts of this article.

Correspondence concerning this article should be addressed to AvshaIom Caspi, Social, Genetic and Developmental Psychiatry Research Centre, 111 Denmark Hill, Institute of Psychiatry, London SE5 8AF, England. Electronic mail may be sent to a.caspi@iop.kcl.ac.uk.
Contemporary interest in the developmental study of early emerging temperamental differences is largely due to the insightful work of Thomas and Chess (see Kagan, 1998). These pediatric psychiatrists found that a majority of children could be grouped into one of three temperamental types which they labeled easy, difficult, and slow to warm up. Repeated assessments of a group of 141 children, studied from the first few years of life to young adulthood, showed that these temperamental profiles were fairly stable over the short run, but in the long run it proved difficult to predict specific adult outcomes for the different groups of children (Chess \& Thomas, 1987, 1990; Thomas, Chess, \& Birch, 1970). Chess and Thomas's observations spawned a great deal of interest among psychiatrists and psychologists, who have since conducted larger studies to inquire about the origins of personality (Rothbart \& Bates, 1998). These subsequent studies have confirmed the existence of the three temperamental types originally identified by Chess and Thomas, but these studies also show that temperamental types, identified in the first 3 years of life, do offer important clues about specific adult outcomes. Some of the most remarkable evidence about continuities in behavioral development comes from the Dunedin Multidisciplinary Health and Development Study, one of the largest longitudinal studies of human development carried out over the past 30 years (Silva \& Stanton, 1996). The purpose of the present article is to summarize these findings about continuities in behavioral development, which have been uncovered by following a cohort of children from age 3 to 21 .

The goal of the research we have conducted in the Dunedin study has been to determine whether there are continuities across the first two decades of life. Some, although not all, of the findings reported in this article have appeared previously, in specialty journals (e.g., criminology, psychiatry, sociology) according to the outcome, and serially as new follow-up data have been collected. (Citations to earlier publications that offer more measurement and statistical detail are provided throughout this article.) To evaluate the strength of continuity, in this article I focus less on the effect size for any particular outcome variable (although I report these too) and more on the pervasive influence of early appearing temperamental differences for life-course development. By perva- 
sive influence I refer to whether temperamental qualities shape behavior in multiple settings and across many domains of social and psychological functioning. As such, I review evidence about the links between children's temperamental qualities at age 3 and their behavior problems at home as well as at school, their personality styles at age 18 , and their interpersonal relationships, work histories, psychiatric disorders, and criminal behavior at age 21. An empirical demonstration that the influence of early temperamental differences is pervasive and affects multiple outcomes underscores the importance of early intervention efforts.

\section{The Dunedin Study}

The Dunedin study is an investigation of the health, development, and behavior of a complete cohort of children born during a 1-year period (between April 1, 1972, and March 31, 1973) in Dunedin, New Zealand's fourth largest city. Perinatal data were obtained at delivery and when the children were later traced for follow-up at age $3 ; 1,037$ individuals $(52 \%$ males and $48 \%$ females; $91 \%$ of the eligible births) participated in the assessment, forming the base sample for the longitudinal study. Since then the participants have been reassessed at ages $5,7,9,11,13,15,18$, and 21 . Although by now the participants are living throughout New Zealand, as well as in Australia, Europe, and North America, the basic procedure for data collection has remained the same: At each assessment wave, we bring each participant back to the Dunedin research unit within 60 days of his or her birthday for a full day of interviews and examinations in which various data (e.g., physical examinations, psychological tests, psychiatric interviews) are collected by different trained examiners. These data are supplemented by questionnaires that are mailed, as developmentally appropriate, to parents, teachers, and peers nominated by the participants themselves.

The Dunedin study is a unique resource for the study of behavjoral development because it combines five ingredients. First, it is a prospective-longitudinal study in which information is obtained about the same persons as they are assessed repeatedly over time. In the absence of prospective studies, some researchers use retrospective studies and ask people to report about their past. Unfortunately, most people are inefficient and inaccurate processors of information about their past. There is little agreement between how people recollect themselves and what is known about them from concurrent data sources. As such, developmental researchers can ill afford to assume that retrospective reports are valid and veridical accounts of the past (Rutter, Maughan, Pickles, \& Simonoff, 1998). The only alternative is to conduct prospective studies in which people are followed and assessed repeatedly in real time.

Second, the Dunedin study is an epidemiological study of a birth cohort. All walks of life are represented in this developmentallongitudinal study. The participants were born to college professors, carpenters, and clerks, as well as to adolescent parents who had not yet entered the labor force. By the time they reached adulthood, some of the participants were already on their way to successful careers as scientists, athletes, and musicians, whereas others were in prisons and mental hospitals. It is a misunderstanding of epidemiology for one to think that it is solely concerned with obtaining prevalence rates or that it is only concerned with describing pathology. The real importance of epidemiology lies in its ability to yield an unbiased understanding of associations be- tween variables, which is especially important for describing and explaining developmental continuity and change across the life course (Costello \& Angold, 1995; Rutter, 1982). The importance of a general population sample is that it avoids those distortions in associations between variables that are very common in volunteer samples or in selected samples of various kinds (e.g., Newman, Moffitt, Caspi, \& Silva, 1998).

Third, the Dunedin study has suffered very little attrition; over $97 \%$ of the individuals in the original study participated in the most recent assessment, which we conducted in 1993-1994, when they were 21 years old. In contrast, many longitudinal studies lose $25-40 \%$ of their initial samples, and attrition is seldom random. When select individuals are lost from a longitudinal study, the validity and generalizability of conclusions about continuities in behavioral development are compromised (Magnusson \& Bergman, 1990).

Fourth, the Dunedin study involves a multidisciplinary team of researchers who have collectively measured a wide variety of outcomes about the study members. This enables us to evaluate the pervasiveness of continuities in personality development across many domains of functioning.

Fifth, the Dunedin study is large enough and has the available data to control for confounding explanations of continuity, including sex differences in prevalence rates, differences in social class background, and differences in intelligence. All analyses described in this article included these controls and, as detailed in the original publications, the continuity effects hold above and beyond these potential artifacts.

\section{Temperamental Qualities Observed at Age 3}

Numerous methods are available today for assessing temperament, but in 1975, when the Dunedin children were 3 years old, there were fewer and less well-developed measures (see Rothbart \& Bates, 1998), with the notable exception of techniques being introduced by Chess and Thomas (1987) and their colleagues (e.g., Graham, Rutter, \& George, 1973). However, child development professionals and clinicians were long ago impressed by the applied importance of ascertaining early emerging temperamental differences, and the absence of standard tools did not deter them from conceiving and modifying various means for assessing such individual differences. Such was the case in the Dunedin study.

At 3 years of age, each study child participated in a $90-\mathrm{min}$ testing session involving cognitive and motor tasks, such as a picture vocabulary test and tests of fine and gross motor coordination. The children were tested by examiners who had no knowledge of their behavioral history. Following the testing, each child's examiner rated the child on 22 different behavioral characteristics (see Table 1) using ratings that were derived from the collaborative Study on Cerebral Palsy, Mental Retardation, and Other Neurological Disorders of Infancy and Childhood (see Goldsmith \& Gottesman, 1981) and that are similar in scope to the behavior ratings contained in Bayley's infant behavior record (e.g., Matheny, 1980). Principal-components analyses of the examiners ratings revealed three replicable factors, labeled Lack of Control, Approach, and Sluggishness (Caspi, Henry, McGee, Moffitt, \& 
Table 1

Behavioral Characteristics Assessed by Examiners in the Dunedin Study

\begin{tabular}{|c|c|}
\hline Item & Description \\
\hline Emotionally labile & $\begin{array}{l}\text { Extreme instability and overreactivity of } \\
\text { emotional responses }\end{array}$ \\
\hline Restless & $\begin{array}{l}\text { Extreme overactivity, inability to sit still, } \\
\text { constantly in motion }\end{array}$ \\
\hline Impulsive & Explosive, uncontrolled behavior \\
\hline Willful & $\begin{array}{l}\text { Extremely assertive, rough, aggressive behavior } \\
\text { lacking in reserve }\end{array}$ \\
\hline Task withdrawal & $\begin{array}{l}\text { Refusal to continue or attempt tasks that appear } \\
\text { difficult }\end{array}$ \\
\hline Requires attention & Constant need for attention or help \\
\hline Fleeting attention & Lacks concentration, brief attention to tasks \\
\hline Lacks persistence & $\begin{array}{l}\text { Little effort to reach a goal, inability to keep } \\
\text { goal or question in mind }\end{array}$ \\
\hline Negativism & $\begin{array}{l}\text { Resistance to directions or to demands of the } \\
\text { situation and the examiner }\end{array}$ \\
\hline Self-critical & Lacks self-confidence in attempting new tasks \\
\hline Easy separation & $\begin{array}{l}\text { Little or no concem around a new person or } \\
\text { setting }\end{array}$ \\
\hline Quick adjustment & Absence of wariness in a novel siruation \\
\hline Friendly & Extreme ease in social interaction \\
\hline Self-confidence & $\begin{array}{l}\text { Pride in performance and willingness to tackle } \\
\text { presented tasks }\end{array}$ \\
\hline Self-reliance & Overt confidence and absorption in test material \\
\hline Flat affect & $\begin{array}{l}\text { Little change in emotional tone, responding to all } \\
\text { activities in the same way }\end{array}$ \\
\hline Passivity & $\begin{array}{l}\text { Placid, sluggish behavior with slow, infrequent } \\
\text { movement }\end{array}$ \\
\hline $\begin{array}{l}\text { Limited } \\
\text { communication }\end{array}$ & $\begin{array}{l}\text { Limited verbal responses, relative absence of } \\
\text { verbal initiations }\end{array}$ \\
\hline Shy & Withdrawn, unresponsive social behavior \\
\hline Malleable & $\begin{array}{l}\text { Passivity and acquiescence to examiner and test } \\
\text { demands }\end{array}$ \\
\hline $\begin{array}{l}\text { Upset by } \\
\text { strangers }\end{array}$ & $\begin{array}{l}\text { Clinging toward mother, inability to separate } \\
\text { even with reassurances }\end{array}$ \\
\hline Fearful & $\begin{array}{l}\text { Acute discomfort and apprehension that } \\
\text { interferes with test performance }\end{array}$ \\
\hline
\end{tabular}

Silva, 1995). ${ }^{1}$ Cluster analyses of these three factors revealed five homogeneous types of children at age 3. Reliability of the clusters was established by replicating the cluster solution on two randomly selected thirds of the available pool of 1,023 children who had complete temperament data at age 3 (for details, see Caspi \& Silva, 1995).

This "typological" or person-centered approach focuses on the configuration of multiple variables within each child rather than on the relative standing of children across single variables; it is concerned with how different variables are organized within the child and how this organization defines different types of children. The well-adjusted type ( $n=405 ; 48 \%$ male), resembling the Chess-Thomas (Chess \& Thomas, 1987) easy type, included children who were capable of self-control when it was demanded of them, who were adequately self-confident, and who did not become unduly upset when confronting new people and situations. The undercontrolled type ( $n=106 ; 62 \%$ male), resembling the Chess-Thomas difficult type, included children who were impulsive, restless, negativistic, distractible, and labile in their emotional responses. The inhibited type ( $n=80 ; 40 \%$ male), resembling the Chess-Thomas slow-to-warm-up type, included children who were socially reticent, fearful, and easily upset by strangers. Thus, like Chess and Thomas before us, we found that approximately $40 \%$ of the children could be placed in the easy category and another $10 \%$ of the children could be placed in the difficult and slow-to-warm-up groups, respectively. In fact, research on personality development has identified these three types of children using different sources of information (e.g., parent reports, observations) and different statistical methods in different parts of the world (e.g., Iceland, Netherlands, Germany, New Zealand, United States), suggesting that these three types are the best candidates for inclusion in a generalizable typology of temperament (Robins, John, Caspi, Moffitt, \& Stouthamer-Loeber, 1996).

We also found two types of children not anticipated by Chess and Thomas (1987). The confident type ( $N=281 ; 52 \%$ male) were zealous, somewhat impulsive, eager to explore the testing materials, and adjusted to the testing situation quickly; however, unlike undercontrolled children they were not impersistent or negativistic. The reserved type ( $n=151 ; 48 \%$ male) were timid and somewhat uncomfortable in the testing session; however, unlike inbibited children their response disposition was not extreme and their caution did not interfere with their task orientation. In this article, I limit my review to our results from comparisons of the well-adjusted, undercontrolled, and inhibited children because these groups replicate across cultures and they also provide an interpretive fit with previous studies about the structure of temperament. In contrast, the generality of additional types, such as the reserved and confident groups, has yet to be replicated in other samples, and it is unclear whether they constitute independent types or whether they can be subsumed within the three replicable types (Robins, John, \& Caspi, 1998). ${ }^{2}$ I turn now to evidence of the connection between temperamental qualities observed at age 3 and psychosocial outcomes gathered using multiple methods in multiple settings from childhood to adulthood.

\section{Temperamental Qualities at Age 3 Predict Children's Behavior Problems}

Because clinical concerns have historically inspired a great deal of interest in the measurement of temperament, it is not surprising that most longitudinal studies have set out to identify links between temperamental styles and behavior problems in childhood

\footnotetext{
${ }^{1}$ Archival research involves some compromises. For example, we have been unable to locate any information about the reliability of these singleassessment examiner ratings. Rather than abandon these ratings, we carried out a contemporary study of interrater reliability on a sample of 83 four-year-old children who, just like the Dunedin children, were administered various cognitive tests and whose behavior was then rated using the same characteristics evaluated in the Dunedin study (Henry, 1998). Interrater reliabilities ranged from .7 to 9 . This does not establish that the Dunedin ratings were reliable, but it does demonstrate they could easily have been so.

${ }^{2}$ Findings about these two groups are available in previous publications that are cited in this article. In general, the confident children resernbled the well-adjusted children in most respects, except that they exhibited some of the impulsivity-but not the negative affect-characteristic of undercontrolled children; for example, as young adults they scored significantly lower on the MPQ Self-Control scale. The reserved children also resembled the well-adjusted children, except that in some respects they exhibited qualities characteristic of inhibited children; for example, as young adults they scored significantly lower on the MPQ Social Potency scale.
} 
and adolescence (Rothbart \& Bates, 1998). The results from some such studies have been difficult to interpret because they are based on reports of temperament and behavior problems obtained from the same rater at different ages, most often on reports provided over time by mothers. Using such reports to estimate behavioral continuity is problematic because observed continuities may reflect not only continuities in children's characteristics but also, to some unknown extent, continuities in maternal characteristics (Bates, 1994). To examine the links between children's temperamental style and their behavior problems without this artifact, we relied on independent data sources.

From ages 5 to 11 , teachers and parents completed the Rutter Child Scale on a biennial basis (for a review see Elander \& Rutter, 1996; McGee, Williams, \& Silva, 1985 for Dunedin details). This questionnaire inquires about the major areas of a child's behavioral and emotional functioning during the previous year and provides scale scores that index extemalizing problems (e.g., fighting, bullying, lying, disobeying) and internalizing problems (e.g., worrying, crying easily, fussing). To examine the associations between children's temperamental styles and their later behavior problems, we standardized ( $z$ scores) the scales within each age period and estimated multiple regression models in which the undercontrolled and inhibited groups were represented by dummy-coded variables and the well-adjusted group served as the reference group. The results showed that undercontrolled children were repeatedly and independently rated as exhibiting more externalizing problems at ages $5,7,9$, and 11 , both by their parents $(b s=.52, .29, .43, .55$, respectively; all $p s<.01)$ and by their teachers $(b s=.35, .32, .22$, .37 , respectively; all $p s<.01$ ). As these findings show, the associations between undercontrolled behavior and externalizing problems were not attenuated by the passage of time and were robust across home and school settings. There was no evidence pointing to comparable links with internalizing problems; neither the undercontrolled nor the inhibited children were likely to suffer significantly more internalizing problems during childhood.

In adolescence, when the participants were 13 and 15 years old, their parents filled out the Revised Behavior Problem Checklist (Quay, 1983), which contains extensive and age-appropriate items tapping both externalizing and internalizing problems. Undercontrolled children continued to exhibit significantly more externalizing behavior problems at this point in the life course $(b s=.31$ and .40 , respectively; $p s<.01$ ), and they also showed evidence of suffering from internalizing problems ( $b \mathrm{~s}=.27$ and .24 , respectively; $p s<.05$ ). In contrast, inhibited children suffered significantly from internalizing problems during adolescence $(b s=.41$ and .33 , respectively; $p s<.01$ ). These findings fit with what is known from other cross-sectional and longitudinal studies: Measures of undercontrolled temperament are related to both externalizing and internalizing problems, and measures of inhibition are more clearly related to internalizing problems (Bates, Wachs, \& Emde, 1994).

\section{Temperamental Qualities at Age 3 Predict Personality Structure at Age 18}

Whereas individual differences in temperament refer to stylistic differences between how children approach and respond to the world, adult personality traits represent the social and cognitive elaborations of these early styles; they index how adults relate to
Table 2

Multidimensional Personality Questionnaire (MPQ) Scale Descriptions

\begin{tabular}{|c|c|}
\hline MPQ Scale & Description of a high scorer \\
\hline Traditionalism & $\begin{array}{l}\text { Desires a conservative social environment; } \\
\text { endorses high moral standards }\end{array}$ \\
\hline Harm avoidance & $\begin{array}{l}\text { Avoids excitement and danger; prefers safe } \\
\text { activities even if they are tedious }\end{array}$ \\
\hline Control & Is reflective, cautious, careful, rational, planful \\
\hline Aggression & $\begin{array}{l}\text { Hurts others for own advantage; will frighten and } \\
\text { cause discomfort for others }\end{array}$ \\
\hline Alienation & $\begin{array}{l}\text { Feels mistreated, victimized, betrayed, and the } \\
\text { target of false rumors }\end{array}$ \\
\hline Stress reaction & Is nervous, vulnerable, sensitive, prone to worry \\
\hline Achievement & $\begin{array}{l}\text { Works hard; enjoys demanding projects and } \\
\text { working long hours }\end{array}$ \\
\hline Social potency & $\begin{array}{l}\text { Is forceful and decisive; fond of influencing others; } \\
\text { fond of leadership roles }\end{array}$ \\
\hline Well-being & $\begin{array}{l}\text { Has a happy, cheerful disposition; feels good about } \\
\text { self and sees a bright future }\end{array}$ \\
\hline Social closeness & $\begin{array}{l}\text { Is sociable, likes people, and turns to others for } \\
\text { comfort }\end{array}$ \\
\hline
\end{tabular}

and think about the world around them (Rutter, 1987). To examine the links between behavioral styles in childhood and personality traits in young adulthood, we assessed the participants' personalities at age 18 using the Multidimensional Personality Questionnaire (MPQ; Tellegen et al., 1988; Tellegen \& Waller, in press), one of the best known contemporary structural models of personality (Church \& Burke, 1994). As summarized in Table 2, the MPQ provides for each person a comprehensive profile of scores on 10 distinct personality traits that define three general superfactors of personality. Constraint is a combination of the Traditionalism, Harm Avoidance and Self-Control scales. Individuals high on this factor tend to endorse social norms, act in a cautious and restrained manner, and avoid thrills. Negative Emotionality is a combination of the Aggression, Alienation, and Stress Reaction scales. Individuals high on this dimension have a low general threshold for the experience of negative emotions such as fear, anxiety, and anger and tend to be involved in antagonistic relationships. Positive Emotionality is a combination of the Achievement, Social Potency, Well-Being, and Social Closeness scales. Individuals high on this dimension tend to view life as being essentially a pleasurable experience. (The MPQ Absorption scale was not included in the MPQ version administered in the Dunedin study.)

Figure 1 shows that the age-18 personality profiles of the three groups of children are very different. At age 18, the undercontrolled children scored low on traits indexing Constraint. They described themselves as reckless and careless (low self-control) and said they enjoyed dangerous and exciting activities (low harm avoidance). They scored high on traits indexing Negative Emotionality. They said that they enjoyed causing discomfort to other persons (high aggression), yet they also reported feeling mistreated, deceived, and betrayed by others (high alienation). In contrast, inhibited children scored high on traits indexing Constraint and low on traits indexing Positive Emotionality. They reported being cautious rather than impulsive (high self-control), they preferred safe activities over dangerous ones (high harm 

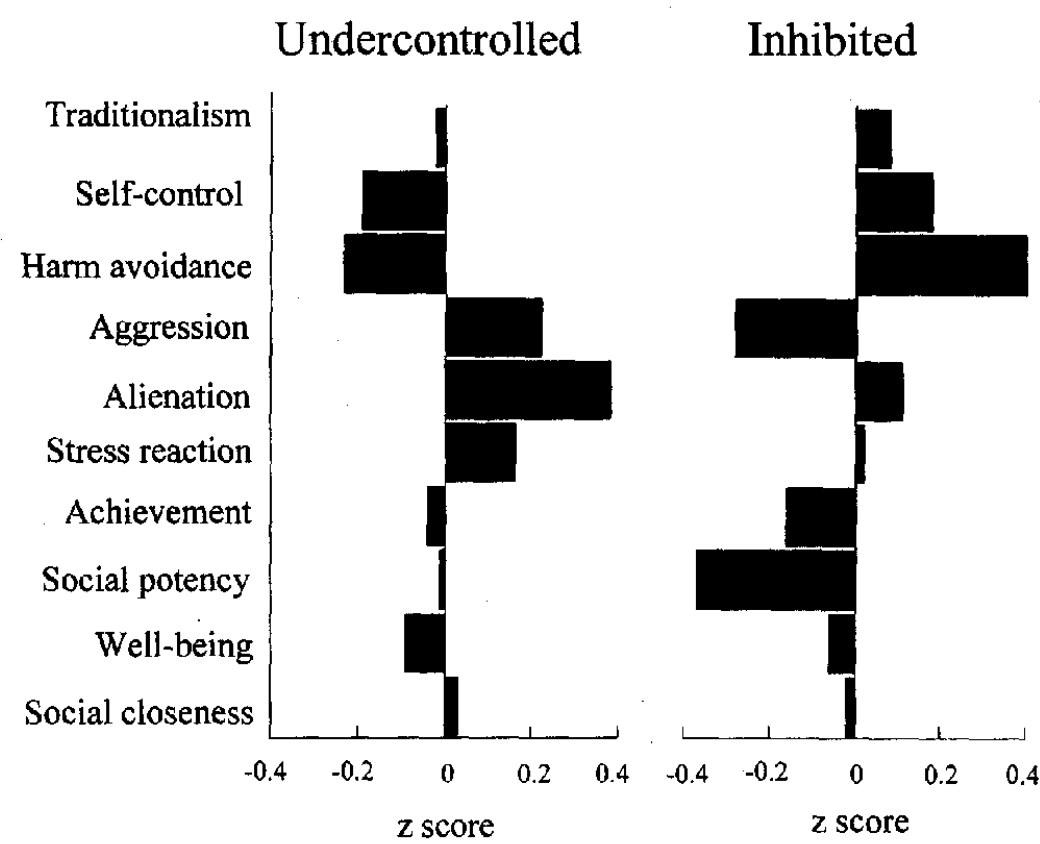

\section{Well adjusted}

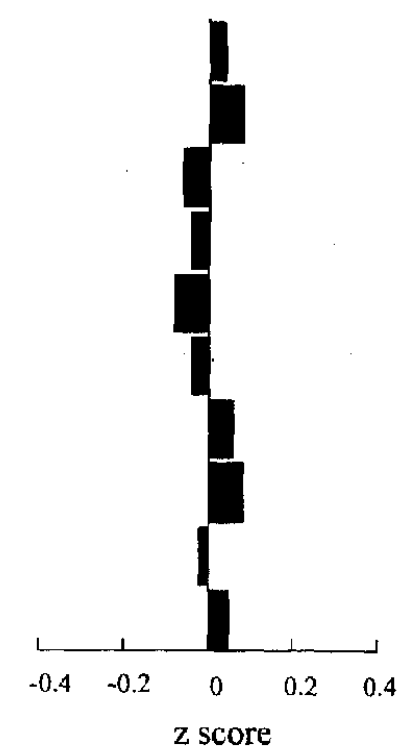

Figure 1. The link between age-3 behavior styles and the study members' Multidimensional Personality Questionnaire (MPQ) profiles at age 18. The figure shows $z$ scores $(M=0, S D=1)$ standardized on the full Dunedin sample. To evaluate the statistical significance of the results, we examined the age-18 differences among the three temperament groups using multiple regression equations in which the undercontrolled $(n=92)$ and inhibited $(n=72$ ) groups were represented by dummy-coded variables and the well-adjusted group ( $n=$ 366) served as the reference category. Traditionalism, $b_{\text {undercontrolled }}=-.06, n s$, and $b_{\text {inhibited }}=.04, n s$; self-control, $b_{\text {underconcrolled }}=-.27, p<.05$, and $b_{\text {inhibited }}=.09, n s$; harm avoidance, $b_{\text {undercontrolled }}=-.17, n s$, and $b_{\text {inhibited }}=.48, p<.001$; aggression, $b_{\text {undercontrolled }}=.25, p<.05$, and $b_{\text {inhibited }}=-.25, p<.05$; alienation, $b_{\text {undercontrolled }}=.46, p<.001$, and $b_{\text {inhibited }}=.14, n s$; stress reaction, $b_{\text {undercontrolled }}=.21, n s$, and $b_{\text {inhibited }}=$ $.05, n s$; achievement, $b_{\text {undercontrolled }}=-.10, n s$, and $b_{\text {inhibited }}=-.24, n s ;$ social potency, $b_{\text {undercontrolled }}=-.08$, $n s$, and $b_{\text {inhibited }}=-.44, p<.001$; well-being, $b_{\text {undercontrolled }}=-.06, n s$, and $b_{\text {inhibited }}=-.03$, ns; social closeness, $b_{\text {undercontrolled }}=-.09, n s$, and $b_{\text {inhibited }}=-.06, n s$.

avoidance), they said they refrained from trying to take advantage of others, and they were unlikely to favor aggressive behavior (low aggression). Finally, they were lacking in social potency-they were submissive, not fond of leadership roles, and had little desire to influence others (low social potency). In summary, as young adults, inhibited children were characterized by an overcontrolled personality and a nonassertive style. The final panel of Figure 1 shows the personality profile of well-adjusted children, whose behavior at age 3 was characterized as age and situation appropriate; their style of approach and response to the testing session was regarded as expectable by the examiners and made for smooth testing. This style was still discernible at age 18: Statistically, well-adjusted children defined normal, average young adults. ${ }^{3}$

Three years later, when the study members were 21 years old, we asked them to nominate someone who knew them well. We mailed questionnaires to these "informants" and asked them to describe the study members using a checklist of adjectives; $95 \%$ of the informants returned completed questionnaires. A factor analysis of this checklist revealed that informant ratings could be grouped into five salient dimensions, which correspond roughly to the five-factor model of personality (McCrae \& Costa, 1997). These informant ratings tend to corroborate the participants' selfreported personality profiles. As shown in Figure 2, undercon- trolled children were rated by people who knew them well as low on Conscientiousness (e.g., not "reliable" or "trustworthy"). In contrast, inhibited children were rated low on Communion (e.g., not "affectionate"), Agency (e.g., not "outgoing" or "confident"), and Vitality (e.g., not "popular" or "healthy"). In addition, undercontrolled and inhibited children were both described as low on Culture (e.g., not "creative" or "good at art").

In combination, these results constitute convergent evidence about the preservation of individual differences in personality style from ages 3 to 21 across three different data sources: from (a) observer ratings at age 3 to (b) self reports at age 18 to (c) informant descriptions at age 21 .

Temperamental Qualities at Age 3 Predict the Quality of Interpersonal Relationships at Age 21

Young adulthood is associated with a unique set of relational challenges, which Erikson (1950) aptly summarized by calling this

\footnotetext{
${ }^{3}$ Caspi and Silva (1995) reported findings based on $862 \mathrm{MPQ}$ protocols completed at the age 18 assessment. After the assessment, we obtained MPQs from an additional 76 participants. The findings reported here are based on the 938 protocols.
} 


\section{Undercontrolled}

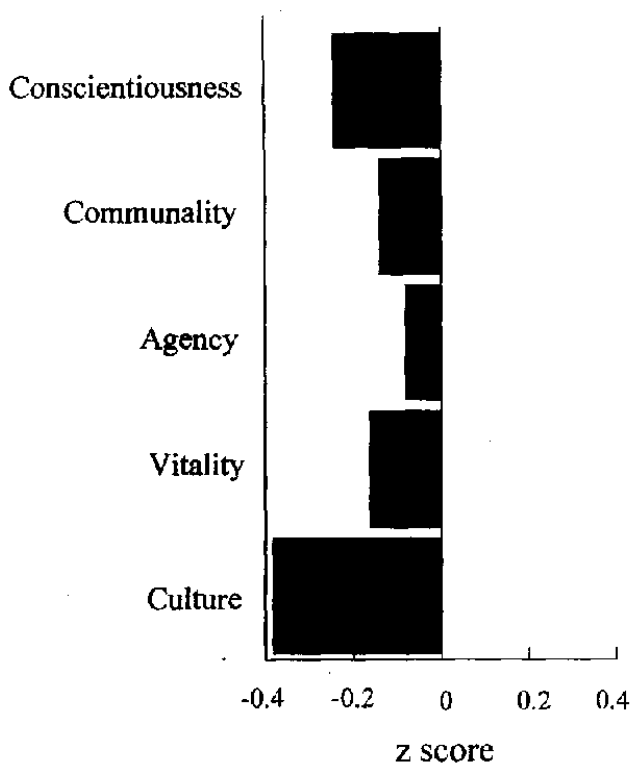

Inhibited

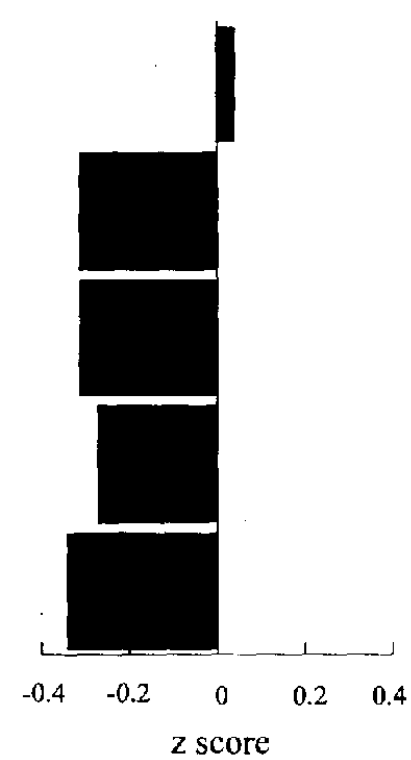

Well adjusted

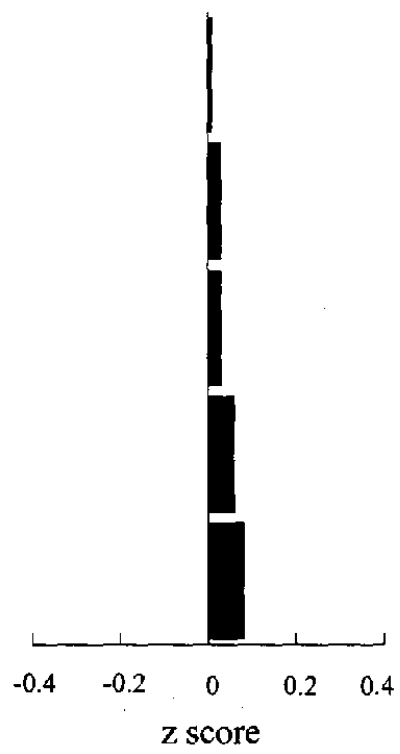

Figure 2. The link between age-3 behavior styles and informant impressions of the study members at age 21 . The figure shows $z$ scores $(M=0, S D=1)$ standardized on the full Dunedin sample. To evaluate the statistical significance of the results, we examined the age-21 differences among the three temperament groups using multiple regression equations in which the undercontrolled $(n=87)$ and inhibited $(n=68)$ groups were represented by dummy-coded variables and the well-adjusted group $(n=351)$ served as the reference category. Conscientiousness, $b_{\text {undercontrolled }}=-.24, p<.05$, and $b_{\text {inhibited }}=-.04, n s$; communion, $b_{\text {undercontrolled }}=-.12$, $n s$, and $b_{\text {inhibied }}=-.24, p<.05$; agency, $b_{\text {underconcrolled }}=-.11, n s$, and $b_{\text {inhibited }}=-.34, p<.05$; vitality, $b_{\text {undercontrolled }}=-.22, n s$, and $b_{\text {inhibited }}=-.34, p<.05$; culture, $b_{\text {undercontrolted }}=-.44, p<.05$, and $b_{\text {inhibited }}=$ $-.40 . p<.001$.

developmental period the stage of "intimacy versus isolation." Would temperamental styles observed at age 3 relate to the negotiation of this life stage? On the basis of our personality findings, we expected that undercontrolled children would experience more conflicted interpersonal relationships, whereas inhibited children would have restricted interpersonal relationships. We examined the study members' interpersonal lives by looking at their relationships with (a) members of their household (including households they set up after leaving their parents' homes) and (b) a romantic partner (Newman, Caspi, Moffitt, \& Silva, 1997).

By age $21,79 \%$ of the participants had left their parents' home. We thus defined home as the study members' current residence and asked them to appraise the quality of interpersonal relationships in their household using the family relations index (Moos \& Moos, 1981). This index assesses the extent of cohesion (e.g., "There is a feeling of togetherness"), expressiveness (e.g., "We tell each other about our personal problems"), and conflict (e.g., "We fight a lot" [reversed]) between members of a household. Figure 3 shows that undercontrolled children had significantly lower scores on the household relations index, reflecting conflict and tension with members of their household in young adulthood.

In addition to interviewing the study members about the general atmosphere of their home environment, we also interviewed them about their love lives. For the purposes of this study, an intimate relationship was defined as a relationship with a romantic partner during the past 12 months that had lasted at least 1 month; $83 \%$ of the study members reported that they were involved in such an intimate relationship. We found no evidence that the three temperament groups differed in their likelihood of being in an intimate relationship, $\chi^{2}(2, N=539)=1.66, n s$. We interviewed those study members who were involved with a romantic partner about their relationship. This structured interview yielded a global measure of relationship quality with items that reflect shared activities and interests (e.g., "We like to spend our free time with each other"), balance of power (e.g., "We are flexible in how we handle differences"), respect and faimess, emotional intimacy and trust, and open communication (e.g., "We are supportive of each other in difficult times"). Figure 3 shows that as young adults, undercontrolled children were involved in more conflicted relationships, as expressed in significantly fewer mutual interests shared with their partners, more unequal balance of power in the relationship, and less intimacy and trust.

\section{Temperamental Qualities at Age 3 Predict the Availability of Social Support in Young Adulthood}

When the participants were at age 21 , we also obtained information about social-support networks by asking them to specify the number of people who could provide them with different types of support (Newman et al., 1997). Material or Practical Assistance measured the number of people who would help with financial or physical assistance when needed. Mentorship and Guidance mea- 


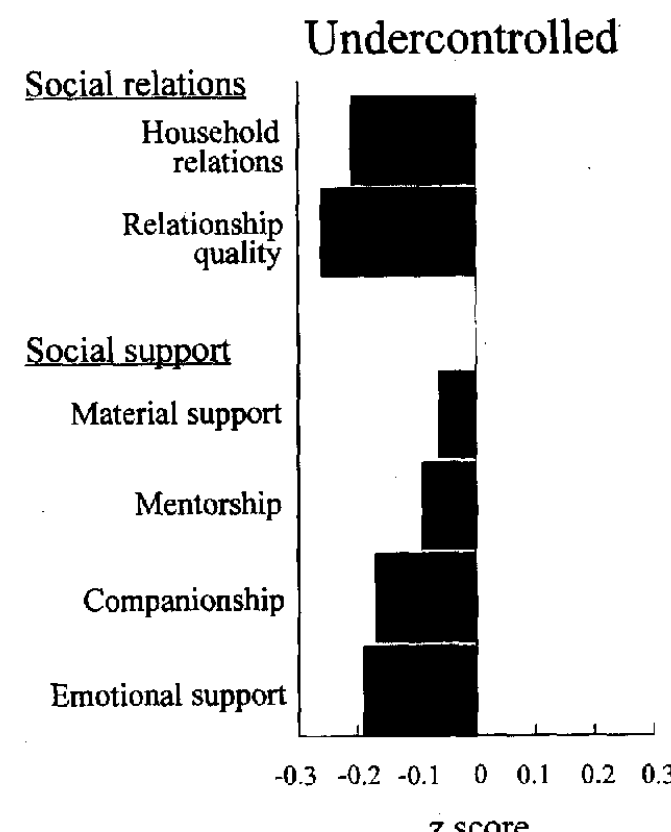

z score
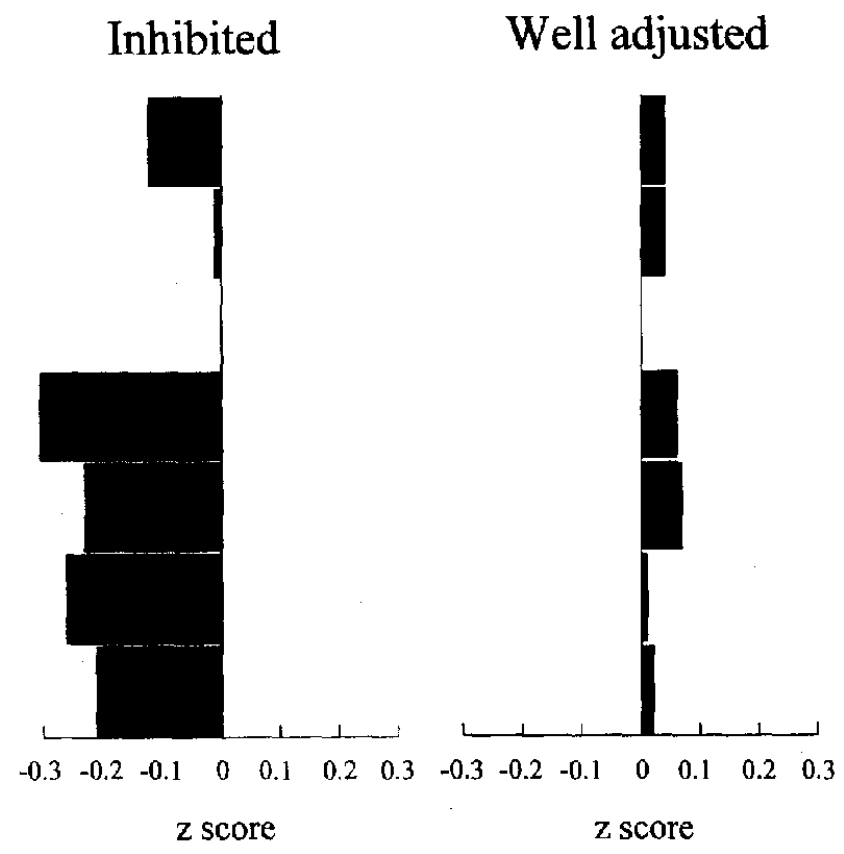

Figure 3. The link between age-3 behavior styles and the study members' interpersonal relations at age 21 . The figure shows $z$ scores $(M=0, S D=1)$ standardized on the full Dunedin sample. To evaluate the statistical significance of the results, we examined the age-21 differences among the three temperament groups using multiple regression equations in which the undercontrolled $(n=72-93)$ and inhibited $(n=62-73)$ groups were represented by dummy-coded variables and the well-adjusted group $(n=307-373)$ served as the reference category. The lower-bound range on the sample sizes is due to the fact that not all study members had a romantic partner about whom to report. Household relations index, $b_{\text {undercontrolled }}=-.25, p<.05$, and $b_{\text {inhibited }}=$ $-.14, n s$; relationship quality, $b_{\text {undercontrolled }}=-.26, p<.05$, and $b_{\text {inhibited }}=-.01$, ns; material support, $b_{\text {undercontrolled }}=-.13, n s$, and $b_{\text {inhibited }}=-.36, p<.01 ;$ mentorship, $b_{\text {undercontrolled }}=-.17, n s$, and $b_{\text {inhibited }}=$ $-.30, p<.05$; companionship, $b_{\text {undercontrolled }}=-.19, n s$, and $b_{\text {inhibited }}=-.27, p<.05$; emotional nurturance, $b_{\text {undercontrolled }}=-.21, n s$, and $b_{\text {inhibited }}=-.19, n s$.

sured the number of people who advise, teach, recommend, or otherwise help smooth the way in navigating the world. Companionship measured the number of people who share interests and provide companionship for pleasurable activities. Nurturance and Emotional Support measured the number of people who provide lasting affiliation, love, and comfort. Consistent with their social reputations for being less affiliative (see Figure 2) as well as with their self-descriptions as lacking lively interest and engagement in their world (see Figure 1), inhibited children reported lower levels of social support as young adults. The results in Figure 3 show that inhibited children had little material support, guidance, or mentorship and reported the smallest sized network of companions.

\section{Temperamental Qualities at Age 3 Predict Unemployment in the Transition to Adulthood}

Entering the labor force and finding employment is one of the most significant role transitions of young adulthood (Petersen \& Mortimer, 1994). Employment yields income, grants training opportunities, and contributes to skill acquisition. It also provides young people a source of vocational identity, a sense of mastery and purpose, and a "stake" in adult institutions. How individuals develop such human capital is of growing interest to psychologists, and the Dunedin results show that early temperamental qualities may play a role in this process (Caspi, Wright, Moffitt, \& Silva, 1998).

We obtained reliable monthly educational and employment histories from the Dunedin study members using a life history calendar that covered the period from their 15th birthday to age 21 . We chose age 15 because it was the end of compulsory schooling for this birth cohort; turning 15 thus offered Dunedin study members the first opportunity to enter the labor force. The Dunedin study members left secondary school at the median age of 17 years 8 months. Both the undercontrolled and the inhibited children left secondary school significantly earlier, on average 3-4 months before the well-adjusted children, but they did so for different reasons. Among those who did not complete 5 years of high school (the maximum number of years), $21 \%$ of the undercontrolled children were asked to leave school, compared with only $3 \%$ and $4 \%$ of the inhibited and well-adjusted children, respectively. These behavioral differences were also apparent once they joined the labor force. About half of the Dunedin study members experienced some unemployment between ages 15 to 21 , and the average length of unemployment was 6 months. Tobit regression models for left-censored data (used because half of the study members were never unemployed) revealed that undercontrolled 3-year-olds were at significantly greater risk for unemploy- 
ment $(b=4.1, p<.05)$ whereas inhibited children were not $(b=2.9, p=.16)$; on average, undercontrolled children grew up to be unemployed 1.5 times as long as other members of the cohort. Some evidence suggests that undercontrolled children were handicapped in the labor market because they continued to bring an aversive interpersonal style to bear on their dealings with others in the workplace; for example, they were 2.5 times (95\% confidence interval: 1.2-5.5) as likely to be fired from a job compared with well-adjusted children. Not surprisingly, by age 21 , undercontrolled children $(b=.33, p<.01)$, but not inhibited children $(b=.16, p=.17$ ), also reported that they relied on benefits from multiple types of governmental support to make ends meet. It is still too early in their lives for us to assess the study members" occupational attainments, but these results about the transition to adulthood suggest that early temperamental qualities may be implicated in different socioeconomic trajectories.

\section{Temperamental Qualities at Age 3 Predict Psychiatric Disorders in Young Adulthood}

Young adulthood is the peak risk period for the development of mental illness (Institute of Medicine, 1994), begging the question Can we foretell who is at risk for psychiatric problems during the transition from adolescence to adulthood? When the study members were 21 years old, we administered to them the Diagnostic Interview Schedule (DIS, version III-R) to obtain diagnoses of mental disorder following criteria established in the Diagnostic and Statistical Manual of Mental Disorders (DSM-III-R) of the American Psychiatric Association (1987). Forty percent of the Dunedin study members met criteria for a psychiatric disorder (Newman et al., 1996), an estimate that is consistent with the prevalence rate of psychiatric disorders for this age group (37\%) as revealed in the U.S. National Comorbidity Survey (Kessler et al., 1994). Mental health problems did not randomly afflict study members. As young adults, undercontrolled (46\%) and inhibited (53\%) children were more likely than well-adjusted children $(38 \%)$ to be diagnosed with a psychiatric disorder. However, the more important question, clinically and theoretically, is whether age-3 behavior styles foretell specific adult psychiatric outcomes (McDevitt, 1986).

We focused on the most prevalent disorders of this age period to determine whether temperament could foretell who is at risk for different types of mental health problems during the transition to adulthood (Caspi, Moffitt, Newman, \& Silva, 1996). We examined the following groupings of psychiatric disorders: (a) anxiety disorders, comprising generalized anxiety disorder, obsessivecompulsive disorder, panic disorder, agoraphobia, social phobia, simple phobia, or any combination of these disorders: (b) mood disorders, including separate diagnoses of major depressiondysthymia versus manic episode; (c) antisocial personality disorder; and (d) alcohol dependence.

Figures 4-7 show the prevalence rates (i.e., cohort base rates) of specific disorders in the Dunedin sample as a whole as well as the rates for well-adjusted, undercontrolled, and inhibited children. Figure 4 shows that age- 3 behavior styles could not distinguish young adults at risk for developing an anxiety disorder. We also tested whether age- 3 behavior could predict specific subtypes of anxiety disorders (e.g., social phobia, agoraphobia), but the results were not significant. Figure 5 shows the link between age-3

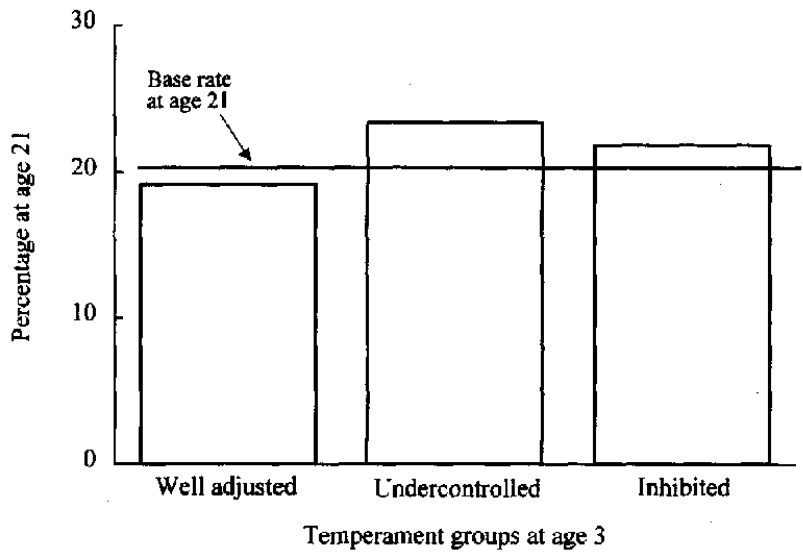

Figure 4. The link between age-3 behavior styles and anxiety disorder at age 21 . To evaluate the statistical significance of the results, we examined the risk of age-21 anxiety disorders among the three temperament groups using logistic regressions in which the undercontrolled ( $n=94$ ) and inhibited ( $n=73$ ) groups were represented by dummy-coded variables and the well-adjusted group ( $n=375$ ) served as the reference category. The odds ratio for the undercontrolled group is $1.2(95 \%$ confidence interval [CI], 0.74-2.2) and for the inhibited group is 1.1 (95\% CI, 0.64-2.1).

behavior styles and mood disorders at age 21 . Inhibited children were significantly more likely to be diagnosed with depression at age 21 , whereas undercontrolled children were not. Although manic depression could not be predicted from age-3 behavior styles, it is of interest that none of the inhibited children had experienced an episode of mania, which is characterized by symptoms of increased activity, inflated self-esteem, and impulsivity. Thus, inhibition showed predictive specificity within the family of mood disorders. Figure 6 shows the association between age- 3 behavior styles and antisocial personality disorder at age 21 . Undercontrolled children were significantly more likely to meet diagnostic criteria for this disorder, which is characterized by predatory, callous, and exploitative behavior that is refractory to contingencies. Figure 7 shows that undercontrolled children were also significantly more likely to be diagnosed with alcohol dependence at age 21 . Inhibited children had elevated rates of alcoholism as well, but this result did not attain statistical significance. Finally, Figure 8 shows the association between age- 3 behavior styles and suicide attempts at age 21. As part of the mental health interview, study members were asked about suicide attempts they had made during the past 12 months. Attempts were counted whether or not they had required medical attention. Suicide attempts were significantly more concentrated among former undercontrolled and inhibited children. In summary, our longitudinal data suggest that early emerging behavioral differences not only act as a persisting risk factor for later psychiatric problems but also can sometimes confer risk for specific forms of psychopathology.

\section{Temperamental Qualities at Age 3 Predict Criminal Behavior at Age 21}

We assessed illegal behavior at age 21 using the Self-Report Delinquency Interview, which is used to study delinquent behavior among young people throughout the Western world (see Moffitt, Silva, Lynam, \& Henry, 1994). Using a reporting period of the 


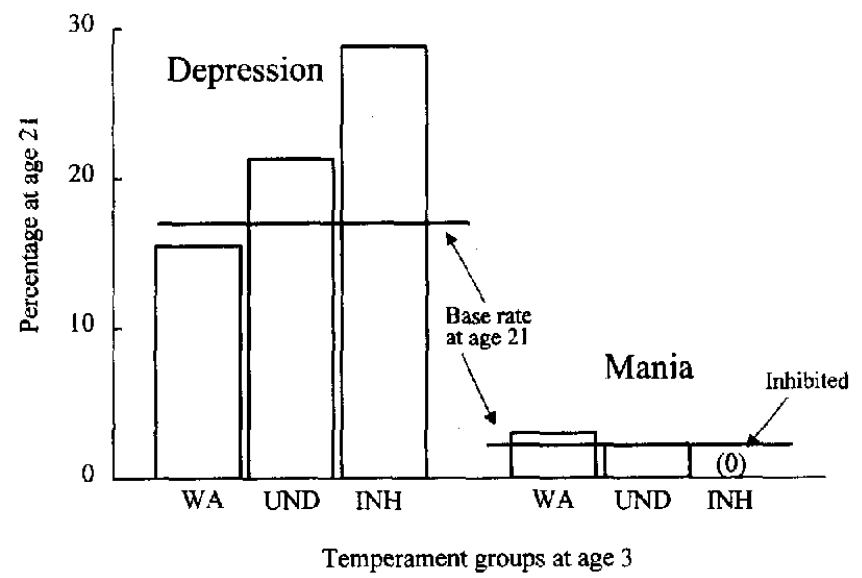

Figure 5. The link between age-3 behavior styles and mood disorders at age 21. To evaluate the statistical significance of the results, we examined the risk of age-21 depression using logistic regressions in which the undercontrolled (UND; $n=94$ ) and inhibited (INH; $n=73$ ) groups were represented by dummy-coded variables and the well-adjusted group (WA; $n=375$ ) served as the reference category. For depression, the odds ratio for the undercontrolled group is 1.5 (95\% confidence interval [CI], 0.852.6) and for the inhibited group is $2.2(95 \% \mathrm{CI}, 1.2-4.0)$. A statistical analysis was not performed for mania as there were no inhibited cases who met diagnostic criteria for this disorder.

previous 12 months, this interview asks the study members whether they engaged in each of 48 different illegal and antisocial behaviors including acts of theft, assault, vandalism, drug trafficking, and fraud. Following standard practice, we created a "variety" index that sums the number of different types of illegal behaviors in which each study member engaged. Variety scores such as these are endorsed by criminologists, as "it appears that the best available operational measure of the propensity to offend is a count of

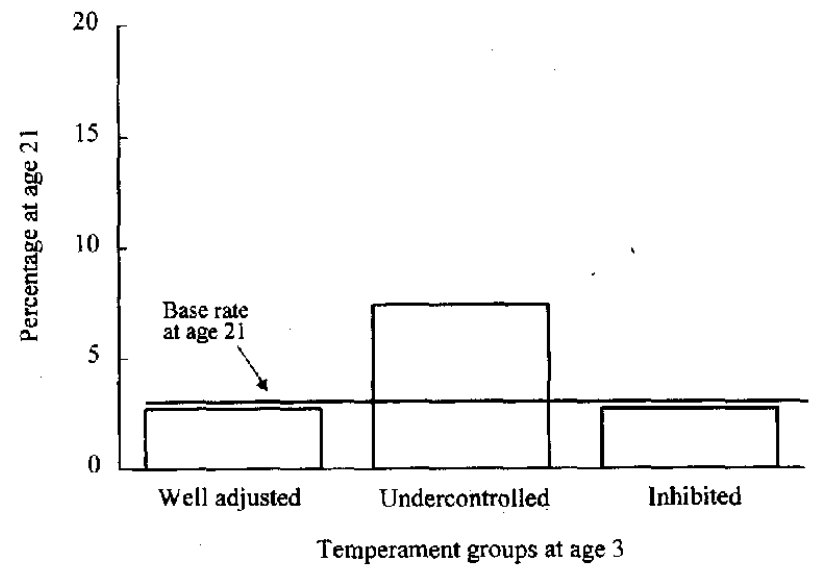

Figure 6. The link between age- 3 behavior styles and antisocial personality disorder at age 21 . To evaluate the statistical significance of the results, we examined the risk of age- 21 antisocial personality disorder using logistic regressions in which the undercontrolled $(n=94)$ and inhibited $(n=73)$ groups were represented by dummy-coded variables and the well-adjusted group $(n=375)$ served as the reference category. The odds ratio for the undercontrolled group is $2.9(95 \%$ confidence interval $[\mathrm{CI}, 1.1-7.9)$ and for the inhibited group is $1.0(95 \% \mathrm{CI}, 0.22-4.7)$.

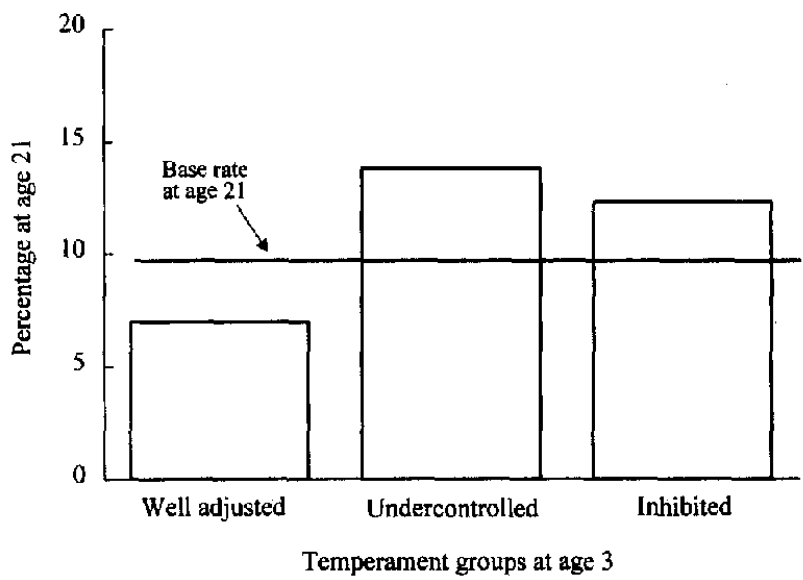

Figure 7. The link between age- 3 behavior styles and alcohol dependence at age 21 . To evaluate the statistical significance of the results, we examined the risk of age-21 alcohol dependence using logistic regressions in which the undercontrolled $(n=94)$ and inhibited $(n=73)$ groups were represented by dummy-coded variables and the well-adjusted group $(n=$ 373) served as the reference category. The odds ratio for the undercontrolled group is 2.1 (95\% confidence interval [CI], 1.1-4.3) and for the inhibited group is 1.8 (95\% CI, 0.84-4.1).

the number of distinct problem behaviors engaged in by a youth (that is, a variety scale)" (Hirschi \& Gottfredson, 1995, p. 134). As shown in Figure 9, undercontrolled children, as young adults, were significantly more likely to be involved in a life of crime.

Official records corroborate these self-reported data. We obtained records of study members' cumulative court convictions at all courts in New Zealand and Australia by searching the central computer systems of the New Zealand police. Conviction records did not include traffic offenses with the exception of driving under

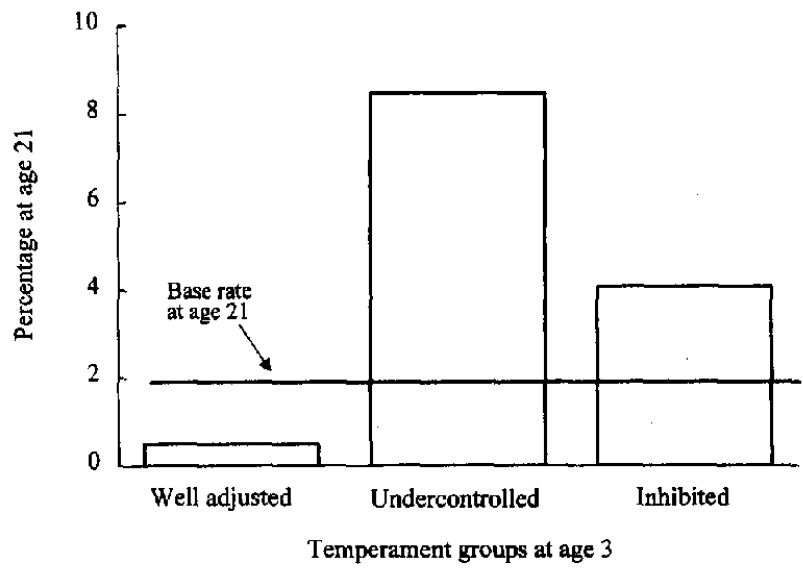

Figure 8 . The link between age- 3 behavior styles and suicide attempts at age 21 . To evaluate the statistical significance of the results, we examined the risk of suicide attempts at age 21 using logistic regressions in which the undercontrolled ( $n=94)$ and inhibited $(n=73)$ groups were represented by dummy-coded variables and the well-adjusted group $(n=371)$ served as the reference category. The odds ratio for the undercontrolled group is 18.4 (95\% confidence interval [CI], 3.5-82.2) and for the inhibited group is 7.4 (95\% CI, 1.2-48.1). 


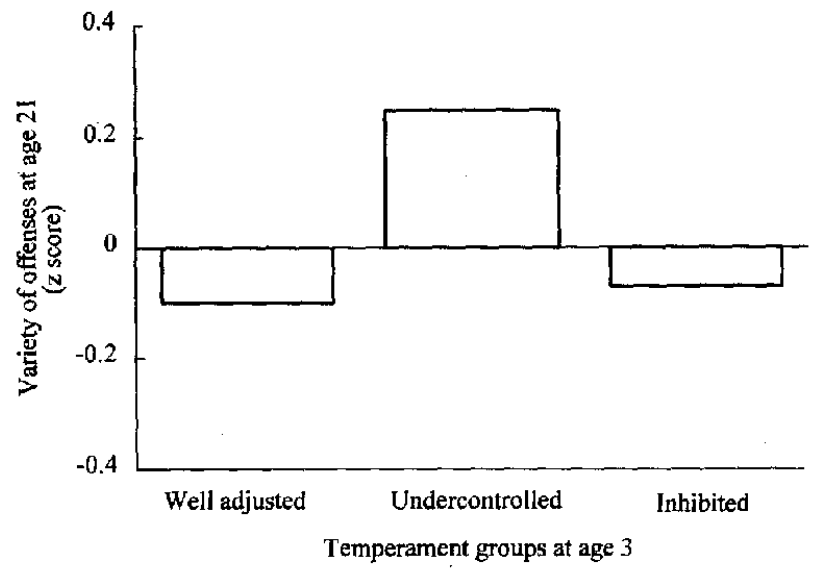

Figure 9. The link between age- 3 behavior styles and variety of criminal offenses self-reported at age 21 . The figure shows $z$ scores $(M=0, S D=$ 1) standardized on the full Dunedin sample. To evaluate the statistical significance of the results, we examined the age-21 differences among the three temperament groups using multiple regression equations in which the undercontrolled ( $n=94)$ and inhibited $(n=73)$ groups were represented by dummy-coded variables and the well-adjusted group $(n=373)$ served as the reference category, $b_{\text {undercontrolled }}=.35, p<.001$, and $b_{\text {inhibited }}=$ $.01, n s$.

the influence of alcohol or criminally negligent driving; $14 \%$ of the study members had been convicted of a crime by age 21 , accounting for a total of 895 convictions. Of special interest are repeat offenders, who have been convicted of two or more offenses. Figure 10 shows that undercontrolled children were significantly more likely to have been convicted of multiple crimes than were inhibited or well-adjusted children.

Our longitudinal data also reveal that early emerging temperamental differences are linked to social attitudes about crime. According to perceptual deterrence theory, individuals may be deterred from crime if they perceive legal consequences as certain, swift, and severe (Williams \& Hawkins, 1986). We thus measured perceived risk of arrest by asking each study member, at age 21 , to indicate how often they thought they would get caught for a specific crime committed on 10 different days (e.g., "If you shoplifted from a store on 10 different days, how many times do you think you would probably get caught for shoplifting?"). We inquired about seven different crimes, including shoplifting, drug use, car theft, assault, burglary, drunk driving, and fraud (Moffitt, Caspi, Dickson, Stanton, \& Silva, 1996). On the whole, the participants thought they would get caught an average of 5 times out of $10(S D=1.7)$. But not all children grew up to perceive the same risks $F(2,533)=5.8, p<.05$. Interestingly, it was the inhibited children who in adulthood most feared getting caught. On average, they thought they would be caught 5.7 times out of 10 , significantly more often than undercontrolled and well-adjusted children, who thought they would get caught 4.7 and 5.1 times out of 10, respectively. Perceptual deterrence theory also argues that informal social sanctions, such as censure by friends and family, may deter individuals from crime. We measured such perceived informal social sanctions by asking the participants to indicate whether they would lose the respect of close friends and family members if those persons knew about their involvement in each of seven illegal behaviors: shoplifting, drug use, car theft, assault, burglary, drunk driving, and fraud. The results showed significant attitudinal differences at age 21 between the three temperament groups, $F(2$, $539)=2.84, p=.05$. Consistent with their personality profile as alienated young adults, undercontrolled children perceived fewer social deterrents to crime (Mean $z$ score $=-.20$ ) than did the inhibited $(-.05)$ and well-adjusted (.06) children.

\section{Conclusion}

A fundamental assumption guiding the study of personality development is that early emerging temperamental differences shape the course of development, its problematic presentations and healthful outcomes (Rutter, 1987). The Dunedin study instantiates this assumption by offering the most comprehensive evidence to date of personality continuities from the first 3 years of life to adulthood.

Assertions about personality continuity are often ambiguous. For example, the boy who has daily temper tantrums when he is 3 years old but weekly tantrums when he is 9 years old has increased his level of emotional control; he has changed in absolute terms. But if he ranks first in temper tantrums among his peers at both ages, he has not changed in relative terms. Further ambiguity arises because the surface manifestations of personality undergo profound transformations with development. For example, the undercontrolled child who has daily temper tantrums in early childhood may refrain from this behavior as an adult. But if he emerges into adulthood as a man who is irritable and moody, we may grant that the surface behavior has changed but claim that the underlying personality type has not. Although the form of behavior changes over time, the course of personality development is said to evidence coherence if the qualities of behavior are preserved over time: "The notion of coherence refers to a pattern of findings where a construct, measured by several different methods, retains

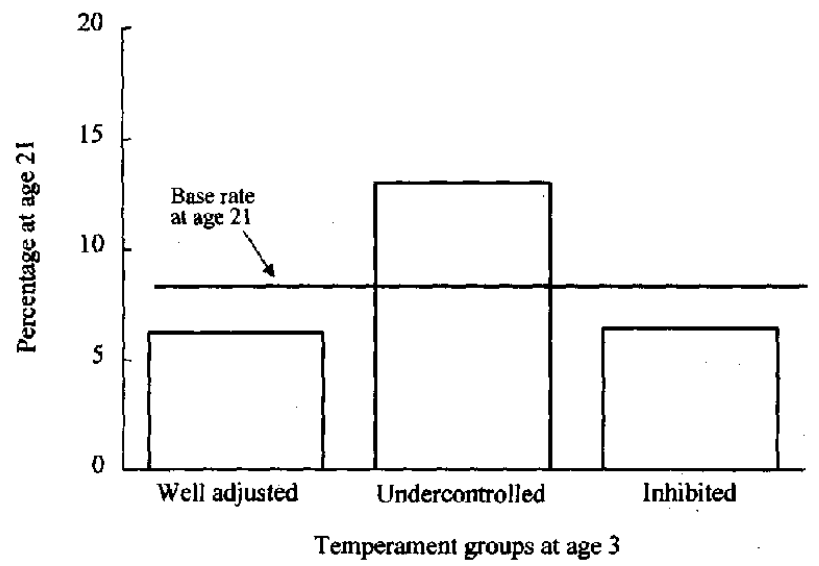

Figure 10. The link between age- 3 behaviot styles and official records of criminal recidivism. To evaluate the statistical significance of the results, we examined the risk of criminal recidivism by age 21 using logistic regressions in which the undercontrolled $(n=100)$ and inhibited $(n=78)$ groups were represented by dumny-coded variables and the well-adjusted group ( $n=388$ ) served as the reference category. The odds ratio for the undercontrolled group is 2.2 (95\% confidence interval $[\mathrm{CI}, 1.1-4.6$ ) and for the inhibited group is 1.0 (95\% CI, $0.38-2.8$ ). 
its psychological meaning as revealed in relationships to a variety of other measures" across time and in different contexts (Ozer, 1986, p. 83).

We have seen evidence of coherence by following a cohort of children from age 3 to age 21 . When observed at age 3 , children classified as undercontrolled ( $10 \%$ of the sample) were described as irritable, impulsive, emotionally labile, and impersistent on tasks. Throughout childhood, their parents and teachers found them difficult to manage. In terms of their personality structure at age 18 , undercontrolled children were characterized not only by high levels of impulsivity and thrill seeking but also by aggression and interpersonal alienation. By age 21 , undercontrolled children reported more employment difficulties and higher levels of interpersonal conflict at home and in their romantic relationships. They had extensive brushes with the law, and their successful assumption of adult roles was compromised by their abuse of alcohol. People who knew them well corroborated this profile of conflicted interpersonal adjustment in describing undercontrolled children grown up as unreliable and untrustworthy.

When observed at age 3 , children classified as inhibited ( $8 \%$ of the sample) were notably shy, fearful, and socially ill-at-ease. As adolescents they suffered from internalizing problems of distress. At age 18, they were characterized by overcontrolled, cautious, and nonassertive personality styles, expressing little desire to take on leadership roles or to exert influence over others. By age 21, they reported lower levels of social support, and their mental health was compromised by depression. People who knew them well corroborated this profile in describing inhibited children grown up as less affiliative, low on social agency, and lacking lively interest and engagement in their worlds.

Finally, the well-adjusted type ( $40 \%$ of the sample) included children whose style of approach and response at age 3 was regarded as age and situation normative; they overcame their initial wariness to the examiner in the testing session and became friendly as the session went on, they displayed appropriate selfcontrol, and although they attempted to cope with challenging tasks, they did not become too upset if the tasks proved too difficult. This style was still discernible in adulthood; statistically, well-adjusted children defined normal, average young adults.

These three groups of children did not behave in the same way in every situation. Instead, we saw predictable and meaningful ways of relating to the environment in different social settings at different ages. The results suggest the hypothesis that the continuities of personality are expressed not in the constancy of behavior across time and diverse circumstances but through the consistency over time in the ways persons characteristically modify their changing contexts as a function of their behavior.

\section{Are These Connections Meaningful?}

From childhood to adulthood, each of the empirical connections uncovered in the Dunedin study represents only a small to medium effect size. Recall, however, that the sources of these connections are behavioral observations of children's temperamental qualities that were made after a 90 -min testing session by an examiner who was otherwise unacquainted with the child. It is also true that age- 3 temperamental qualities explained only a meager amount of the variance in any single adult outcome. However, the importance of the reported findings lies not in the prediction of a single outcome but rather in the pervasive association between temperamental qualities at age 3 and multiple, independently ascertained indexes of psychosocial functioning at different ages and in different settings. Moreover, because the effects of personality differences accumulate over a lifetime, a focus on a single outcome variable measured at a single point in time will result in an underestimate of the extent of continuity in behavioral development (Caspi, Bem, \& Elder, 1989; Rutter \& Rutter, 1993). Abelson (1985) makes this point in noting that differences between baseball players are trivial if considered on the basis of a single at bat but become meaningful over the course of a game, a season, and a career. So it is on the playing field of life.

Small effect sizes have been defended as important elsewhere (e.g., Ahadi \& Diener, 1989; Prentice \& Miller, 1992; Rosenthal \& Rubin, 1982), but another way to think about the consequences of continuity is to abandon traditional metrics of social science research and examine the real-world implications of early emerging behavioral differences. Consider antisocial behavior. Crimes impose costs on victims and entail costs to society. To obtain estimates of the cost of crime, I relied on the work of economists who have quantified in dollar terms the cost of each type of crime committed. These estimates take into account costs to the criminal justice system as well as to victims (e.g., reduced productivity, out-of-pocket expenses). Because an economic analysis of the costs of crime is not available for New Zealand per se, I used estimates calculated for the United States to assign a dollar value to crimes (e.g., assault, drunk driving, burglary, car theft) for which Dunedin study members have been convicted on a per crime basis (see Cohen, Miller, \& Rossman, 1994, especially Tables 16 and 17, p. 128; Miller, Cohen, \& Wiersema, 1996, especially Table 2, p. 9). Assuming that the relative costs of crime are fairly comparable across nations, the results show that undercontrolled children imposed more costs to society ( $M=\$ 24,722$ ) than did the inhibited $(M=\$ 3,093)$ or well-adjusted $(M=\$ 720)$ children. A test of group differences is statistically significant at conventional levels, but that misses the point: Developmental continuities are pervasive; they have consequences not only for the welfare of the individual but also for the welfare of the wider community.

It is important to place evidence from the Dunedin study about developmental connectedness in historical perspective. Throughout the 20 th century, professional opinion and public advice have been swayed by claims and counterclaims about the extent of continuity and discontinuity in human development (Block, 1984). Only 20 years ago, one of the century's leading child psychologists assailed what he believed was a misguided "faith in connectedness" and suggested instead that early psychological characteristics and experiences have few implications for later behavior (Kagan, 1980). The fact that Dunedin data chart connections from the first few years of life (as early as age 3 ) to young adulthood is thus a significant achievement, for this was and remains a contested claim (Lewis, 1999).

\section{How Early Can We Tell?}

The Dunedin study's behavioral data were first collected only at age 3, after a lot of development already occurred. Can we foretell adult life patterns from psychological characteristics at even earlier ages? The second year of life may be the crucial dividing line for 
predicting adult personality differences because of the intercorrelated cognitive-emotional changes that take place during this period. During the second year of life, perceptual and cognitive changes enable children to master object permanence and engage in symbolic play (Kagan, 1981). Self-conscious emotions such as embarrassment and shame also begin to appear at this time (Astington, 1993). These capacities may be necessary for children to form mental representations of their social world and to develop beliefs and expectations that are then affirmed by an expanding and reactive social environment (Kagan, 1984). It is possible that continuity or predictability may not emerge until infants experience these major developmental reorganizations during the second year of life.

There are other reasons to doubt the feasibility of prediction prior to the second year of life. It is possible that much of the observed variation in infant behavior is due to transient conditions, such as temporary allergies. As these conditions disappear with growth, so may their associated behavioral tendencies (Kagan, 1984). It is also possible that predictability may not emerge until a later age because early psychological differences are especially likely to be modified by the child's subsequent experiences with the environment (Chess \& Thomas, 1987). Temperamental dimensions in infancy are the "personality" of the newborn, but whether they show continuity depends on the degree of "fit" between the child's temperamental characteristics and the socialization context (Wachs, 1994).

But before giving up on predicting later personality from infant temperament, one should consider the parallel case of predicting IQ. For many years, psychologists argued that intellectual performance scores obtained in the earliest years of life correlated poorly with IQ scores at later ages, implying that infancy and toddlerhood may be especially plastic developmental periods for intellectual status. But new evidence challenges this claim, as studies have shown that assessments of habituation and recognition memory in the first year of life predict later IQ quite well (McCall \& Carriger, 1993). What implications do these findings have for the prediction of personality? According to Asendorpf (1992), these findings highlight the distinction between the stability of individual differences and the continuity of psychological constructs. Correlations across time may be low either because the rank order of individuals has changed over time or because the construct intelligence is indexed by different behaviors at different ages. Thus, it may be that, compared with previous measures of infant intelligence, habituation and recognition paradigms tap an information processing mechanism that is more similar to those skills tapped by later IQ tests. With regard to the prediction of personality differences, it may be that behavioral indicators in early childhood and those in adulthood have unequal validity coefficients; that is, they do not adequately reflect the behavioral expression of the same personality construct. Further advances in prediction will be made only if researchers are able to operationalize the same trait construct at different ages.

\section{From Prediction to Explanation}

The goal of this article has been to summarize evidence from one study about continuities in personality development, from early childhood to adulthood. It was beyond the objective of this summary to test hypotheses about processes that maintain continuity or prompt change. Ultimately, a complete developmental approach to the study of personality also must explain how continuities emerge and document what processes promote change. It is important to bear in mind that in the study of personality continuity and change, the twin goals of prediction and explanation are not always best served by the same types of data collection methods and designs. Longitudinal studies that gather repeated data on persons across the life course are the lifeblood of research on personality development because they can demonstrate the extent of continuity and change in behavioral development, document the consequences for later development of early emerging personality features, and identify the changing expressions of early emerging personality types across age and in diverse developmental settings (Block, 1993). However, the social, cognitive, and behavioral processes underlying continuity do not merely unfold across swaths of time. Rather, according to theories now dominant, these processes take place in the context of new interpersonal interactions with different people in different developmental settings; parents, siblings, peers, coworkers, and partners are variously drawn in at different points in the life course as accomplices in the maintenance of continuity (Wachtel, 1994). This has two implications for research on processes underlying personality continuity. First, to the extent that the most important sources of continuity (and change) are to be found in interpersonal settings, the ideal study of individual development ought to be conceived of as a study of social relationships, one in which longitudinal participants are successively studied alongside their significant others at different points in the life course (e.g., Kandel, Davies, \& Baydar, 1990). Second, the study of continuity and change must include both global ratings of individual differences (to document connections across time and circumstance) and minute-to-minute assessments of social interactions (to document how behavior patterns are sustained and potentially altered) (Patterson \& Bank, 1990). Each strategy provides different but crucial information about continuity and change in personality development. The Dunedin study design is strong for documenting connections across time, but other designs are needed to explore how social transactions maintain continuity or prompt change.

I have discussed in previous works how early temperamental differences become elaborated over time to shape multiple outcomes (Caspi, 1998). The process of developmental elaboration refers to the mechanisms by which those temperamental attributes that are part of each individual's genetic heritage accumulate response strength through their repeated reinforcement and become elaborated into cognitive structures strongly primed for accessibility. There are many kinds of personenvironment transactions, but three play particularly important roles both in promoting the continuity of personality and in controlling the trajectory of the life course itself. Reactive transactions occur when different individuals exposed to the same environment experience it, interpret it, and react to it differently. Evocative transactions occur when an individual's personality evokes distinctive responses from others. Proactive transactions occur when individuals select or create environments of their own. These person-environment transactions represent probabilistic connections that strengthen response 
dispositions across the age-graded life course as individuals assume new roles and relationships and interpret and modify their experiences in corresponding social settings. ${ }^{4}$

The key word in the previous sentence was probabilistic. Longitudinal studies of the natural history of personality development underscore that continuity is more likely than change. But the fact that natural-development studies point to the connectedness of behavioral development across the life course does not preclude the possibility of planned interventions, nor does it negate the possibility of naturally occurring change. In part, some change comes about because the course of personality development resembles a "random walk," a series of stochastic events, or fortuitous chance encounters, that collectively and cumulatively contribute to differences between individuals and that also have the capacity to deflect life paths (Bandura, 1982; Meehl, 1978, p. 811). Other change comes about because the intersection of psychological dispositions and social-structural or ecological characteristics creates differential opportunities for the expression of individual differences (Laub \& Sampson, 1993). For example, undercontrolled boys are significantly less likely to become involved in crime if they stay in school (Henry, Caspi, Moffitt, Harrington, \& Silva, in press). And finally, some change in the natural history of development comes about because people do respond to reinforcers and punishers, whether delivered as explicit or implicit contingencies. For example, inhibited children respond differently than noninhibited children to different parenting practices (Kochanska, 1997), and parental interventions can generate "lawful" or predictable discontinuities in early development (Park, Belsky, Putnam, \& Crnic, 1997). Responsivity to new contingencies is not limited to the childhood years and to formative relationships with parents. New relationships in adulthood also offer the potential for turning points, as suggested by the finding that marital attachment is associated with change in the criminal behavior of antisocial youth and may thus help to explain emergent discontinuities in adult development (Laub, Nagin, \& Sampson, 1998).

Why, then, against this background of potential change, are bath maladaptive and adaptive patterns of behavior sustained across the life course? For the most part, it is because the course of behavioral development is shaped and elaborated in environments that covary with personality differences (Scarr \& McCartney, 1983). In the early years of life, person-environment covariation occurs because of the joint transmission of genes and culture from parents to offspring. Given that parents and children resemble each other in temperamental qualities, children whose difficult temperament might be curbed by firm discipline will tend to have parents who are inconsistent disciplinarians, and the converse is also true: Warm parents tend to have infants with an easy temperament. Later in life, personenvironment covariation occurs because people choose situations and select partners who resemble them, reinforcing their earlier established interactional styles. Across the life coursefrom one's family of origin to one's family of destinationbehavioral development takes place in environments that are correlated with individual differences in personality. And even though it is not possible to predict chance encounters, personality differences influence how even these fortuitous events are subjectively experienced. The child thus becomes the father of the man (at $p<.05$ ).

${ }^{4}$ I deliberately use the term person-environment "transaction" rather than "interaction" or "correlation" because the first term is methodologically neutral, whereas the latter terms have specific statistical connotations. I also deliberately use the term "person-environment" rather than "geneenvironment" because I do not presuppose knowledge about the etiology of these individual differences and because these transactions may operate in relation to behaviors that are not heritable.

\section{References}

Abelson, R. (1985). A variance explanation paradox: When a little is a lot. Psychological Bulletin, 97, 129-133.

Ahadi, S., \& Diener, E. (1989). Multiple determinants and effect sizes. Journal of Personality and Social Psychology, 56, 398-406.

American Psychiatric Association. (1987). Diagnostic and statistical manual of mental disorders (3rd ed., rev.). Washington, DC: Author.

Asendorpf, J. B. (1992). Beyond stability: Predicting inter-individual differences in intra-individual change. European Journal of Personality, 6 , 103-117.

Astington, J. W. (1993). The child's discovery of the mind. Cambridge, MA: Harvard University Press.

Bandura, A. (1982). The psychology of chance encounters and life paths. American Psychologist, 37, 747-755.

Bates, J. E. (1994). Parents as observers of their children's development. In S. Friedman \& H. C. Haywood (Eds.), Developmental follow-up: Concepts, domains, and methods. San Diego, CA: Academic Press.

Bates, J. E., Wachs, T. D., \& Emde, R. N. (1994). Toward practical uses for biological concepts of temperament. In J. E. Bates \& T. D. Wachs (Eds.), Temperament: Individual differences at the interface of biology and behavior (pp. 275-306). Washington, DC: American Psychological Association.

Block, J. (1984). From infancy to adulthood: A clarification. Child Development, 51, 622-623.

Block, J. (1993). Studying personality the long way. In D. Funder, R. D. Parke, C. Tomlinson-Keasey, \& K. Widaman (Eds.), Studying lives through time: Personality and development (pp. 9-41). Washington, DC: American Psychological Association.

Caspi, A. (1998). Personality development across the life course. In W. Damon (Series Ed.) \& N. Eisenberg (Vol. Ed.), Handbook of child psychology: Vol. 3. Social, emotional, and personality development (pp. 311-388). New York: Wiley.

Caspi, A., Bem, D. J., \& Elder, G. H., Jr. (1989). Continuities and consequences of interactional styles across the life course. Journal of Personality, 57, 375-406.

Caspi, A., Henry, B., McGee, R. O., Moffitt, T. E., \& Silva, P. A. (1995). Temperamental origins of child and adolescent behavior problems: From age 3 to age 15. Child Development, 66, 55-68.

Caspi, A., Moffitt, T. E., Newman, D. L., \& Silva, P. A. (1996). Behavioral observations at age 3 predict psychiatric disorders: Longitudinal evidence from a birth cohort. Archives of General Psychiatry, 53, 10331039.

Caspi, A., \& Silva, P. A. (1995). Temperamental qualities at age 3 predict personality traits in young adulthood: Longitudinal evidence from a birth cohort. Child Development, 66, 486-498.

Caspi, A., Wright, B., Moffitt, T. E., \& Silva, P. A. (1998). Early failure in the labor market: Childhood and adolescent predictors of unemployment in the transition to adulthood. American Sociological Review, 63, 424451 .

Chess, S., \& Thomas, A. (1987). Origins and evolution of behavior 
disorders: From infancy to early adult life. Cambridge, MA: Harvard University Press.

Chess, S., \& Thomas, A. (1990). Continuities and discontinuities in ternperament. In L. Robins \& M. Rutter (Eds.), Straight and devious pathways from childhood to adulthood (pp. 205-220). New York: Cambridge University Press.

Church, T. A., \& Burke, P. J. (1994). Exploratory and confirnatory tests of the Big Five and Tellegen's three- and four-dimensional models. Joumal of Personality and Social Psychology, 66, 93-114.

Cohen, M. A., Miller, T. R., \& Rossman, S. B. (1994). The costs and consequences of violent behavior in the United States. In A. J. Reiss, Jr. \& J. A. Roth (Eds.), Understanding and preventing violence: Consequences and control (pp. 67-166). Washington, DC: National Academy Press.

Costello, E. J., \& Angold, A. (1995). Developmental epidemiology. In D. Cicchetti \& D. J. Cohen (Eds.), Developmental psychopathology (Vol. 1, pp. 23-56). New York: Wiley.

Elander, J., \& Rutter, M. (1996). Use and development of the Rutter parents' and teachers' scales. International Journal of Methods in Psychiatric Research, 6, 63-78.

Erikson, E. (1950). Childhood and society. New York: Norton.

Goldsmith, H. H., \& Gottesman, I. I. (1981), Origins of variation in behavioral style: A longitudinal study of temperament in young twins. Child Development, 52, 91-103.

Graham, P., Rutter, M., \& George, S. (1973). Temperamental characteristics as predictors of behavior disorders in children. American Journal of Orthopsychiatry, 43, 328-339.

Henry, B. (1998). Reliability and validity of an observational measure of early-emerging individual differences among pre-school children. Unpublished manuscript, Colby College.

Henry, B., Caspi, A., Moffitt, T. E., Harrington, H. L., \& Silva, P. A. (in press). Staying in school protects boys with poor self-regulation in childhood from later crime: A longitudinal study. International Journal of Behavioral Development.

Hirschi, T., \& Gottfredson, M. R. (1995). Control theory and the lifecourse perspective. Studies on Crime and Crime Prevention, 4, 131-142.

Institute of Medicine, Committee on Prevention of Mental Disorders, Division of Biobehavioral Sciences and Mental Disorders. (1994). Reducing risks for mental disorders: Frontiers for preventive intervention research. Washington, DC: National Academy Press.

Kagan, J. (1980). Perspectives on continuity. In O. G. Brim, Jr. \& J. Kagan (Eds.), Constancy and change in human development (pp. 26-74). Cambridge, MA: Harvard University Press.

Kagan, J. (1981). The second year. Cambridge, MA: Harvard University Press.

Kagan, J. (1984). The nature of the child. New York: Basic Books.

Kagan, J. (1998). Biology and the child. In W. Damon (Series Ed.) \& N. Eisenberg (Vol. Ed.), Handbook of child psychology: Vol. 3. Social, emotional, and personality development (pp. 177-236). New York: Wiley.

Kandel, D. B., Davies, M., \& Baydar, N. (1990). The creation of interpersonal contexts: Homophily in dyadic relationships in adolescence and young adulthood. In L. N. Robins \& M. Rutter (Eds.), Straight and devious pathways from childhood to adulthood (pp. 221-241). New York: Cambridge University Press.

Kessler, R. C., McGonagle, K. A., Zhao, S., Nelson, C. B., Hughes, M., Eshleman, S., Wittchen, H. U., \& Kendler, K. S. (1994). Lifetime and 12-month prevalence of DSM-IU-R psychiatric disorders in the United States: Results from the National Comorbidity Study. Archives of General Psychiatry, 51, 8-19.

Kochanska, G. (1997). Multiple pathways to conscience for children with different temperaments: From toddlerhood to age 5. Developmental Psychology, 33, 228-240.

Laub, J. H., Nagin, D. S., \& Sampson, R. J. (1998). Good marriages and trajectories of change in criminal offending. American Sociological Review, 63, 225-238.

Laub, J. H., \& Sampson, R. J. (1993). Turning points in the life course: Why change matters to the study of crime. Criminology, 31, 301-325.

Lewis, M. (1999). On the development of personality. In Pervin \& O. P. John (Eds.), Handbook of personality theory and research (2nd ed., pp. 327-346). New York: Guilford Press.

Magnusson, D., \& Bergman, L. (Eds.). (1990). Data quality in longitudinal research. New York: Cambridge University Press.

Matheny, A. P., Jr. (1980). Bayley's Infant Behavior Record: Behavioral components and twin analyses. Child Development, 51, 1157-1167.

McCall, R. B., \& Carriger, M. S. (1993). A meta-analysis of infant habituation and recognition memory performance as predictors of later 1Q. Child Development, 64, 57-79.

McCrae, R. R., \& Costa, P. T., Jr. (1997). Personality trait structure as a human universal. American Psychologist, 52, 509-516.

McDevitt, S. (1986). Continuity and discontinuity of temperament in infancy and early childhood: A psychometric perspective. In R. Plomin \& J. Dunn (Eds.), The study of temperament: Changes, continuities and challenges (pp. 27-39). Hillsdale, NJ: Erlbaum.

McGee, R., Williams, S. M., \& Silva, P. A. (1985). Factor structure and correlates of ratings of inattention, hyperactivity, and antisocial behavior in a large sample of 9-year-old children from the general population. Journal of Consulting and Clinical Psychology, 53, 480-490.

Meehl, P. J. (1978). Theoretical risks and tabular asteriks: Sir Karl, Sir Ronald, and the slow progress of soft psychology. Journal of Consulting and Clinical Psychology, 46, 806-834.

Miller, T. R., Cohen, M. A., \& Wiersema, B. (1996). Victim costs and consequences: $A$ new look (National Institute of Justice Publication No. NCJ155282). Washington, DC: U.S. Department of Justice.

Moffitt, T. E., Caspi, A., Dickson, N., Stanton, W., \& Silva, P. A. (1996). Childhood-onset versus adolescent-onset antisocial conduct problems in males. Development and Psychopathology, 8, 399-424.

Moffitt, T. E., Silva, P. A., Lynam, D., \& Henry, B. (1994). Self-reported delinquency: New Zealand's Dunedin Multidisciplinary Health and Development Study. In J. Junger-Tas \& G. J. Terlouw (Eds.), The international self-report delinquency project (pp. 354-369). Amsterdam: Kugler.

Moos, R., \& Moos, B. (1981). Family Environment Scale manual. Palo Alto, CA: Consulting Psychologists Press.

Newman, D. L., Caspi, A., Moffitt, T. E., \& Silva, P. A. (1997). Antecedents of adult interpersonal functioning: Effects of individual differences in age 3 temperament. Developmental Psychology, 33, 206-217.

Newman, D. L., Moffitt, T. E., Caspi, A., Magdol, L., Silva, P. A., \& Stanton, W. (1996). Psychiatric disorder in a birth cohort of young adults: Prevalence, comorbidity, clinical significance, and new case incidence from age 11 to 21 . Journal of Consulting and Clinical Psy. chology, 64, 552-562.

Newman, D. L., Moffitt, T. E., Caspi, A., \& Silva, P. A. (1998). Comorbid mental disorders: Implications for treatment and sample selection. Journal of Abnormal Psychology, 107, 305-311.

Ozer, D. J. (1986). Consistency in personality: A methodological framework. New York: Springer.

Park, S.-Y., Belsky, J., Putnam, S., \& Crnic, K. (1997). Infant emotionality, parenting, and 3-year inhibition: Exploring stability and lawful discontinuity in a male sample. Developmental Psychology, 33, 218-227.

Patterson, G. R., \& Bank, L. (1990). Some amplifying mechanisms for pathologic processes in families. In M. R. Gunnar \& E. Thelen (Eds.), Minnesota symposia on child psychology (Vol. 22, pp. 167-209). Hillsdale, NJ: Erlbaum.

Petersen, A. C., \& Mortimer, J. T. (Eds.). (1994). Youth unemployment and society. Cambridge, England: Cambridge University Press.

Prentice, D. A., \& Miller, D. T. (1992). When small effects are impressive. Psychological Bulletin, 112, 160-164. 
Quay, H. C. (1983). A dimensional approach to behavior disorder: The Revised Behavior Problem Checklist. School Psychology Review, 12, 144-249.

Robins, R. W., John, O. P., \& Caspi, A. (1998). The typological approach to studying personality. In R. B. Caims, L. R. Bergman, \& J. Kagan (Eds.), Methods and models for studying the individual (pp. 135-157). Thousand Oaks, CA: Sage.

Robins, R. W., John, O. P., Caspi, A., Moffitt, T. E., \& Stouthamer-Loeber, M. (1996). Resilient, overcontrolled, and undercontrolled boys: Three replicable personality types. Journal of Personality and Social Psychology, 70, 157-171.

Rosenthal, R., \& Rubin, O. (1982). A simple, general purpose display of magnitude of experimental effect. Joumal of Educational Psychol. ogy, 74, 166-169.

Rothbart, M., \& Bates, J. E. (1998). Temperament. In W. Damon (Series Ed.) \& N. Eisenberg (Vol. Ed.), Handbook of child psychology: Vol. 3. Social, emotional, and personality development (pp. 105-176). New York: Wiley.

Rutter, M. (1982). Epidemiological-longitudinal approaches to the study of development. In W. A. Collins (Ed.), Minnesota symposia on child psychology (Vol. 15, pp. 105-144). Hillsdale, NJ: Erlbaum.

Rutter, M. (1987). Temperament, personality, and personality disorder. British Journal of Psychiatry, 150, 443-458.

Rutter, M., Maughan, B., Pickles, A., \& Simonoff, E. (1998). Retrospective recall recalled. In R. B. Cairns, L. R. Bergman, \& J. Kagan (Eds.), Methods and models for studying the individual (pp. 219-241). Thousand Oaks, CA: Sage.

Rutter, M., \& Rutter, M. (1993). Developing minds. New York: Basic Books.
Scarr, S., \& McCartney, K. (1983). How people make their own environments: A theory of genotype $\rightarrow$ environment effects. Child Development, 54, 424-435.

Silva, P. A., \& Stanton, W. (Eds.). (1996). From child to adult: The Dunedin study. Oxford, England: Oxford University Press.

Tellegen, A., Lykken, D. T., Bouchard, T. J., Wilcox, K. J., Segal, N. L., \& Rich, S. (1988). Personality similarity in twins reared apart and together. Journal of Personality and Social Psychology, 6, 1031-1039.

Tellegen, A., \& Waller, N. G. (in press). Exploring personality through test construction: Development of the Multidimensional Personality Questionnaire. In S. R. Briggs \& J. M. Cheek (Eds.), Personality measures: Development and evaluation. Greenwich, CT: JAI Press.

Thomas, A., Chess, S., \& Birch, H. G. (1970). The origins of personality. Scientific American, 223, $102-109$.

Wachs, T. D. (1994). Fit, context, and the transition between temperament and personality. In C. F. Halverson, Jr., G. A. Kohnstamm, \& R. P. Martin (Eds.), The developing structure of temperament and personality from infancy to adulthood (pp. 209-220). Hillsdale, NJ: Erlbaum.

Wachtel, P. L. (1994). Cyclical processes in personality and psychopathology. Journal of Abnormal Psychology, 103, 51-54.

Williams, K. R., \& Hawkins, R. (1986). Perceptual research on general deterrence: A critical review. Law and Society Review, 20, 545-572.

Received October 7, 1998

Revision received May 16, 1999

Accepted June 2, 1999 